\title{
AVALIAÇÃO DO COMPORTAMENTO DE METAIS EM UMA CÉLULA EXPERIMENTAL DE RESÍDUOS SÓLIDOS URBANOS NA CIDADE DE CAMPINA GRANDE-PB
}

\author{
J. M. VIEIRA NETO ${ }^{1}$, V. E. D. MONTEIRO ${ }^{2}$, M. C. MELO $^{3}$ \\ ${ }^{1}$ Instituto Federal de Educação, Ciência e Tecnologia do Sertão Pernambucano, Coordenação de \\ Edificações \\ ${ }^{2}$ Universidade Federal de Campina Grande, Unidade Acadêmica de Engenharia Civil \\ ${ }^{3}$ Universidade Federal de Campina Grande, Unidade Acadêmica de Saúde \\ E-mail para contato: joao.melo@ifsertao-pe.edu.br
}

\begin{abstract}
RESUMO - Os resíduos sólidos urbanos podem conter elevadas concentrações de contaminantes químicos, metais e solventes químicos que ameaçam os ciclos naturais onde são despejados. Dessa forma, esta pesquisa visa determinar o comportamento dos íons metálicos em uma célula experimental, lisímetro, de resíduos sólidos urbanos (RSU) da cidade de Campina Grande/PB com o intuito de entender a evolução desses íons ao longo do tempo e comparar com o processo de biodegradação. Para isso, foi construído um lisímetro na Universidade Federal de Campina Grande (UFCG) preenchido com resíduos sólidos urbanos da cidade de Campina Grande-PB e amostras foram coletadas mensalmente e submetidas a processos de lixiviação e solubilização, sendo analisadas as concentrações de alumínio, manganês, ferro e cálcio. Os resultados dos testes de lixiviação permitiram classificar os resíduos como "Classe I Perigosos", por apresentarem concentrações de metais acima dos limites estabelecidos.
\end{abstract}

\section{INTRODUÇÃO}

O termo resíduo é definido por Mulholland \& Dyer (1999) como um produto não desejado em um processo, que em grande parte não apresenta valor agregado. Os resíduos sólidos surgem das atividades humanas e de animais, através de acúmulos de resíduos agrícola, industrial e mineral e da vida urbana, que não apresentam mais utilidade e é uma consequência das necessidades dos seres humanos (Pinto, 2005). Com isso, um material que é utilizado pelo consumidor pode gerar em todo seu processo, resíduos que necessitam ser dispostos adequadamente. Segundo, Pinto (2005), a disposição é a última etapa de um resíduo, seja de origem residencial, coletado e transportado a aterro sanitário, seja lodo municipal e industrial de estações de tratamento, resíduo de incineradores, compostagem ou outras fontes de resíduos, não apresentando uma utilização pela sociedade.

São várias as formas de tratamento e disposição dos resíduos sólidos urbanos que são comumente escolhidas, dentre outras, em função de custo, da área disponível e da necessidade do município. Os aterros sanitários têm sido bastante utilizados como forma de disposição final, principalmente nos países subdesenvolvidos, pois são de baixo custo comparado com outras técnicas e possuem praticidade para execução e monitoramento (Garcez, 2009). 
A composição dos resíduos influencia na degradação biológica e impõe características em aterros que experimentam uma série de processos físicos, químicos, físico-químicos e biológicos (Monteiro, 2003).

A composição dos resíduos sólidos urbanos pode conter elevadas concentrações de contaminantes que estão presentes em pilhas, baterias, jornais, tintas, tecidos, têxteis, enlatados, inclusive em alimentos, os quais para serem produzidos necessitam de substâncias à base de metais pesados e outros componentes tóxicos (Melo, 2003). Nesse tipo de resíduo, estão incluídos produtos químicos (cianureto, pesticidas e solventes), metais (mercúrio, cádmio, chumbo, alumínio, cromo, ferro, cobalto, níquel, cobre, zinco) e solventes químicos que ameaçam os ciclos naturais onde são despejados (Kraemer, 2005). De acordo com a Organização Mundial de Saúde (OMS), os metais são responsáveis por inúmeras enfermidades, desde simples alergia até problemas respiratórios, cancerígenos e em algumas situações que podem levar à morte. Diversas são as consequências do lançamento desses resíduos com elevados níveis de periculosidade, destacando-se as doenças causadas aos seres vivos e a contaminação de lençóis freáticos e de cursos de água. Neste sentido, procurar alternativas para atenuar e/ou remover os metais pesados tem sido uma das preocupações dos órgãos ambientais, das indústrias e das instituições brasileiras de pesquisas.

Dentre as alternativas de disposição dos resíduos sólidos urbanos, os aterros sanitários se constituem como uma das mais adequadas. Porém, os aterros não podem ser vistos como simples local de armazenamento, pois se torna indispensável à otimização de projetos e a aplicação de metodologias operacionais capazes de assegurar, de modo estável, a evolução dos processos de degradação e estabilidade geotécnica do aterro. Assim, entende-se como aterro o local onde os resíduos são depositados de forma controlada no solo. Uma vez depositados, os resíduos se degradam naturalmente por via biológica até a mineralização da matéria biodegradável, em condições fundamentalmente anaeróbias (Campos, 2010).

De acordo com a literatura técnica, o líquido produzido na biodegradação dos resíduos, denominado de lixiviado, pode ser considerado como uma matriz de extrema complexidade, composta por: matéria orgânica dissolvida (formada principalmente por metano, ácidos graxos voláteis, compostos húmicos e fúlvicos), compostos orgânicos xenobióticos (representados por hidrocarbonetos aromáticos, compostos de natureza fenólica e compostos organoclorados alifáticos), macrocomponentes inorgânicos (dentre os quais se destacam $\mathrm{Ca}$,

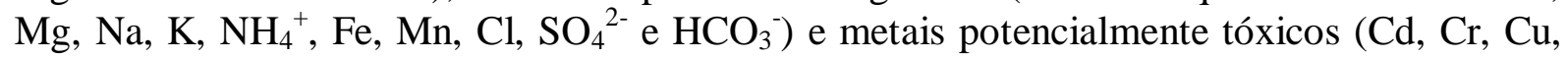
$\mathrm{Pb}, \mathrm{Ni}$ e $\mathrm{Zn})$.

Conforme Ferreira (2006), o lixiviado produzido no início da disposição dos resíduos, fase em que se encontra $\mathrm{O}_{2}$ disponível, apresenta valores altos de DBO e DQO, e elevadas concentrações de sais dissolvidos. Há uma tendência à solubilização dos metais pesados, ou seja, os metais são transferidos da fração sólida para o lixiviado. Na ausência de oxigênio, ou seja, (fase anaeróbia) o pH do lixiviado sobe a valores mais neutros, na faixa de 6,8 a 8 e os valores nas concentrações de DBO e DQO e metais pesados se reduzem.

Os metais pesados não costumam ser os maiores responsáveis na contaminação de água subterrânea pelo lixiviado de resíduos urbanos. A grande preocupação ambiental, nesse caso, se deve à tendência a se acumular nos tecidos dos seres vivos, podendo migrar e sofrer 
magnificação biológica na cadeia alimentar, resultando em diversos efeitos tóxicos (Ehrig, 1989).

Os metais pesados presentes no lixiviado sofrem forte atenuação, principalmente por sorção e precipitação. Podem ser encontrados em formas variadas podendo interagir com os componentes do solo, propiciando a formação de novos compostos. Em decorrência das diversas formas encontradas e possibilidades de interação, a capacidade dos metais pesados serem retidos ou liberados irá depender das propriedades químicas, físicas e biológicas do solo, assim como da forma química com que o metal foi aplicado, sendo que o potencial contaminante depende das inter-relações que ocorrem nessas diferentes fases. (Christensen \& Kjeldsen, 1989).

No intuito de conhecer melhor o funcionamento de aterros de resíduos sólidos urbanos, uma técnica bastante interessante são as células experimentais que permitem obter parâmetros para projetos, dimensionamento, construção e monitoramento desses aterros. Além disso, normas técnicas que atualmente são muitas vezes inadequadas podem ser reformuladas ou aprimoradas a partir dos estudos desenvolvidos em células experimentais também denominadas de lisímetros (Monteiro et al., 2006).

Dentro desse contexto, esta pesquisa visa determinar o comportamento dos metais em uma célula experimental, lisímetro, de resíduos sólidos urbanos (RSU) da cidade de Campina Grande-PB com o intuito de entender o comportamento desses metais ao longo do tempo a fim de comparar com a evolução do processo de biodegradação dos resíduos sólidos urbanos, bem como para contribuição de desenvolvimento e aperfeiçoamento de projetos de aterros sanitários, fazendo com que se entenda melhor sobre os mecanismos de contaminação dos resíduos após sua disposição final, contribuindo para o fornecimento de dados a cerca da realidade dos RSU da cidade.

\section{MATERIAL E MÉTODOS}

\subsection{Construção da célula experimental}

Para o desenvolvimento desse trabalho, inicialmente foi construída uma célula experimental (lisímetro) na Universidade Federal de Campina Grande (UFCG). O lisímetro foi construído a partir de alvenaria de tijolos manuais e possui dimensões de 3,0 $\mathrm{m}$ de altura, $2,00 \mathrm{~m}$ de diâmetro interno e um volume total de aproximadamente $9 \mathrm{~m}^{3}$. A estrutura foi apoiada sobre uma base de concreto, fixada com auxílio de argamassa, e como sistema de impermeabilização do lisímetro foi utilizado uma camada de solo com uma altura de $0,30 \mathrm{~m}$ e $0,20 \mathrm{~m}$ na base e na cobertura do lisímetro, respectivamente.

A instrumentação instalada no lisímetro foi de acordo com a literatura técnica, sendo realizadas algumas adaptações para o melhoramento das análises dos resultados (Leite, 2008). Com o intuito de realizar medições sob condições conhecidas e/ou controladas (Monteiro, 2003), a instrumentação da célula experimental foi composta por: piezômetro, termopares, medidores de recalques superficiais e em profundidade e tubo para drenagem de gases. 


\subsection{Preenchimento da célula experimental com RSU}

O lisímetro foi preenchido com resíduos sólidos urbanos de três bairros da cidade de Campina Grande/PB (Catolé, Mirante e Conjunto Argemiro de Figueiredo), os quais fazem parte de uma mesma rota de coleta e que pertencem à classes sociais distintas. A coleta dos resíduos foi realizada pela empresa LIDER, através de um caminhão compactador com capacidade de aproximadamente 9 toneladas. Ao término da coleta, os RSU's foram encaminhados para o local em que foi construído o lisímetro e foram seguidas as seguintes etapas: descarregamento dos resíduos sólidos urbanos através do caminhão compactador; homogeneização dos resíduos; quarteamento da amostra, com duas pilhas de RSU sendo descartadas; homogeneização da amostra resultante do quarteamento e abertura das sacolas.

O preenchimento do lisímetro foi iniciado com a colocação da camada de solo impermeável de base e, em seguida, adicionou-se uma camada de brita para auxiliar a drenagem de líquidos lixiviados, evitando sua contaminação por meio da lixiviação e deslocamento do resíduo. Com a camada de base finalizada, o lisímetro foi preenchido com os RSU's da pilha resultante por meio de uma máquina retroescavadeira que levava estes resíduos, anteriormente pesados, até a célula experimental, com o intuito de serem depositados manualmente. À medida que os RSU's eram acondicionados no lisímetro, era realizada a compactação com o auxílio de um soquete manual, até atingir uma cota préestabelecida de $2,70 \mathrm{~m}$. A colocação da instrumentação, em cotas pré-estabelecidas, foi realizada à medida que os RSU's iriam sendo compactado em camadas;

Após o preenchimento do lisímetro com os resíduos até a cota pré-estabelecida, ocorreu uma regularização dos RSU's, com uma camada fina de solo, onde foram depositadas duas placas de recalque. Após a colocação das placas, ocorreu a execução da camada final de cobertura da célula experimental.

\subsection{Monitoramento}

O monitoramento do lisímetro ocorreu durante um período de 2 anos, entre outubro de 2009 e outubro de 2011, sendo a amostra inicial coletada durante o preenchimento da célula experimental. Em seguida forma realizadas coletas mensais para realização das análises de metais. Após 7 meses de monitoramento as análises passaram a ser realizadas bimestralmente, devido à escassez de recursos financeiros.

As coletas das amostras foram realizadas numa camada intermediária da célula experimental à uma distância de $1,65 \mathrm{~m}$ do topo do lisímetro através de três orifícios equidistantes com diâmetro de $100 \mathrm{~mm}$, onde coletava-se cerca de $900 \mathrm{~g}$ de resíduos, que eram acondicionados em sacos plásticos com fechamento zip lock e encaminhadas ao laboratório, conforme técnicas de coleta e conservação (CETESB, 1986).

\subsection{Análises periódicas}

Para a avaliação das concentrações de metais nos resíduos sólidos urbanos, foram realizados os testes de lixiviação e de solubilização do material. Os ensaios de lixiviação foram realizados conforme metodologia descrita pela ABNT (2004) - NBR 10.005 e os de solubilização foi seguindo a metodologia descrita pela ABNT (2004) - NBR 10.006. 
As análises de determinação de metais foram realizadas com os extratos lixiviados e solubilizados, pelo método da espectrofotometria de absorção atômica, no qual os metais são expressos na sua forma elementar. Os metais analisados nesta pesquisa foram o alumínio, o manganês, o ferro e o cálcio.

\section{RESULTADOS E DISCUSSÃO}

Nesse trabalho foram analisadas, ao longo do tempo, as concentrações de alumínio, manganês, ferro e cálcio.

A Figura 1 apresenta os resultados obtidos para a concentração de alumínio, manganês e ferro nos resíduos sólidos urbanos ao longo do tempo.

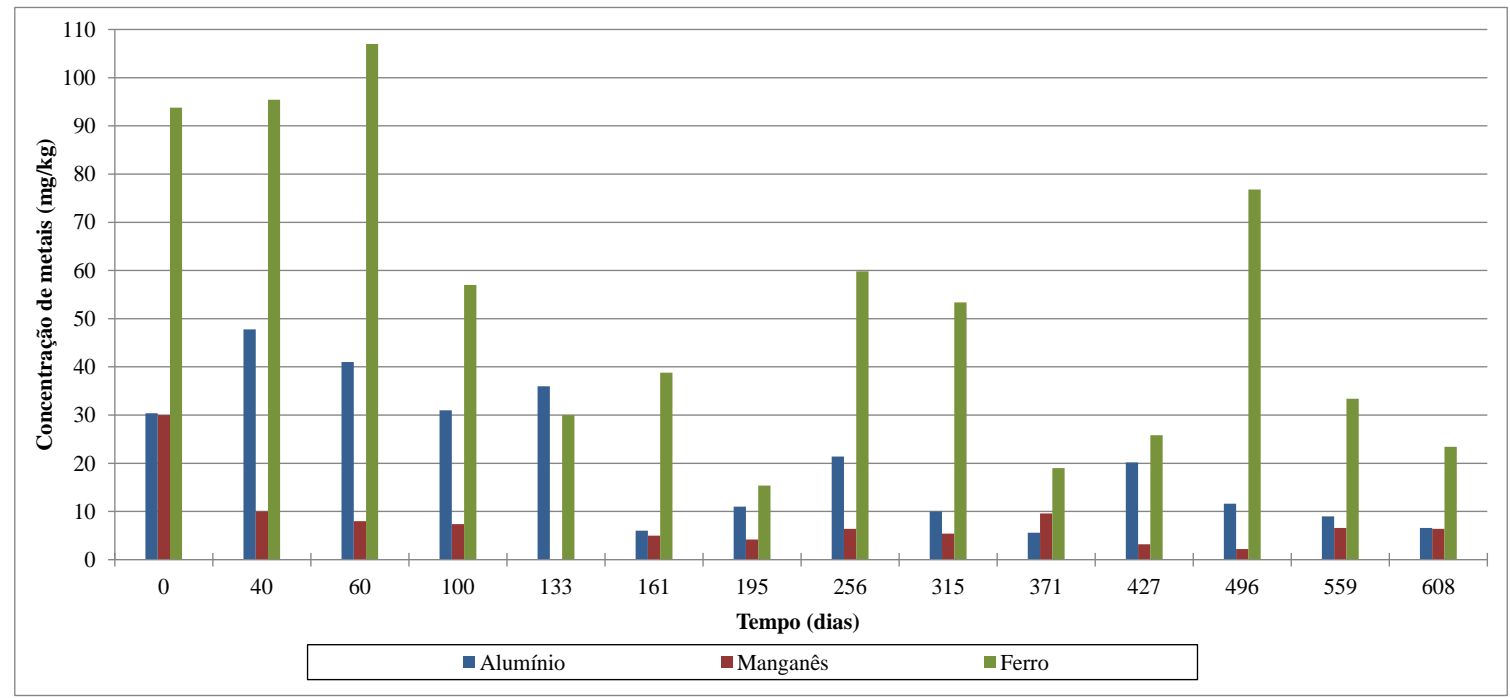

Figura 1 - Concentração de alumínio, manganês e ferro nos resíduos sólidos urbanos do lisímetro ao longo do tempo.

Através da Figura 1 percebe-se que no início do monitoramento foram detectadas elevadas concentrações de alumínio $(30,40 \mathrm{mg} / \mathrm{kg})$ e de manganês $(30,00 \mathrm{mg} / \mathrm{kg})$, as quais tendem a diminuir ao longo do tempo, o que pode ser uma consequência do processo de dissolução dos resíduos causando o carreamento desse metal para camadas mais profundas do lisímetro.

De acordo com a literatura, o alumínio é um metal que pode causar problemas em $\mathrm{pH}$ em torno de 5,50 e é especialmente tóxico em pH abaixo de 5,00 devido ao fato de que a solubilidade desse elemento aumenta com a diminuição do pH (Mesquita Filho \& Souza, 1986). O pH encontrado no início do monitoramento deste trabalho foi de 5,34, o que favorece o aumento da solubilidade do alumínio. O aumento da sua solubilidade potencializa a possibilidade de contaminação do solo e de corpos hídricos por esse metal devido à sua lixiviação.

A elevada concentração de manganês no início do monitoramento está associada provavelmente também ao fato do baixo $\mathrm{pH}$ no início do estudo. Semelhantemente ao alumínio, em condições ácidas o manganês tem sua capacidade de solubilização elevada. 
A concentração de ferro no lisímetro no início do monitoramento foi de 93,8 mg/kg e, ao longo do tempo, o seu valor variou bastante, o que pode ser explicado pelo fato de que o ferro é um elemento comum e utilizado em inúmeras constituições tanto da indústria alimentícia como em outros tipos de indústria. Além disso, na camada de cobertura há a presença de ferro que é carreado para a massa de resíduos e se agrega, aumentando a sua concentração.

De acordo com Brito (2007), a concentração máxima de ferro nos resíduos sólidos deve ser de, no máximo, 6,00 mg/kg de ferro. Percebe-se que, em todo o monitoramento, essa concentração foi acima do limite, chegando a apresentar picos de 107,00 mg/kg em 60 dias de monitoramento. Essas elevadas concentrações de ferro causam grande preocupação com relação à contaminação do solo e de corpos hídricos devido à elevada solubilidade desse elemento.

De acordo com a ABNT (2004) - NBR 10.004, para que um resíduo, submetido a um processo de lixiviação, seja classificado como perigoso (Classe I), ele deve apresentar ao menos um metal com concentração igual ou maior que $4,00 \mathrm{mg} / \mathrm{kg}$. Uma análise da Figura 1 mostra que as concentrações de alumínio, manganês e ferro encontradas nos resíduos sólidos urbanos de Campina Grande foi de, no mínimo, 5,60 mg/kg, 2,20 mg/kg e 15,40 mg/kg, respectivamente, o que caracteriza esses resíduos como perigosos, pois a concentração dos três metais estudados apresentou valores acima do limite máximo estabelecido pela norma (ABNT (2004) e Brito (2007)), chegando a uma concentração de 47,80 mg/kg de alumínio, $30,00 \mathrm{mg} / \mathrm{kg}$ de manganês e $107,00 \mathrm{mg} / \mathrm{kg}$ de ferro.

Em testes de solubilização, a concentração de alumínio encontrada foi de $9,40 \mathrm{mg} / \mathrm{kg}$, valor tal que deveria ser de, no máximo, $0,8 \mathrm{mg} / \mathrm{kg}$, ainda de acordo com a ABNT (2004) NBR 10.004. Assim, caso a capacidade de lixiviação desse elemento fosse reduzida, o resíduo poderia ser classificado como Classe II A - Não-perigoso Não-Inertes, o que não aconteceu.

A Figura 2 apresenta os resultados obtidos para a concentração de cálcio nos resíduos sólidos urbanos do lisímetro ao longo do tempo.

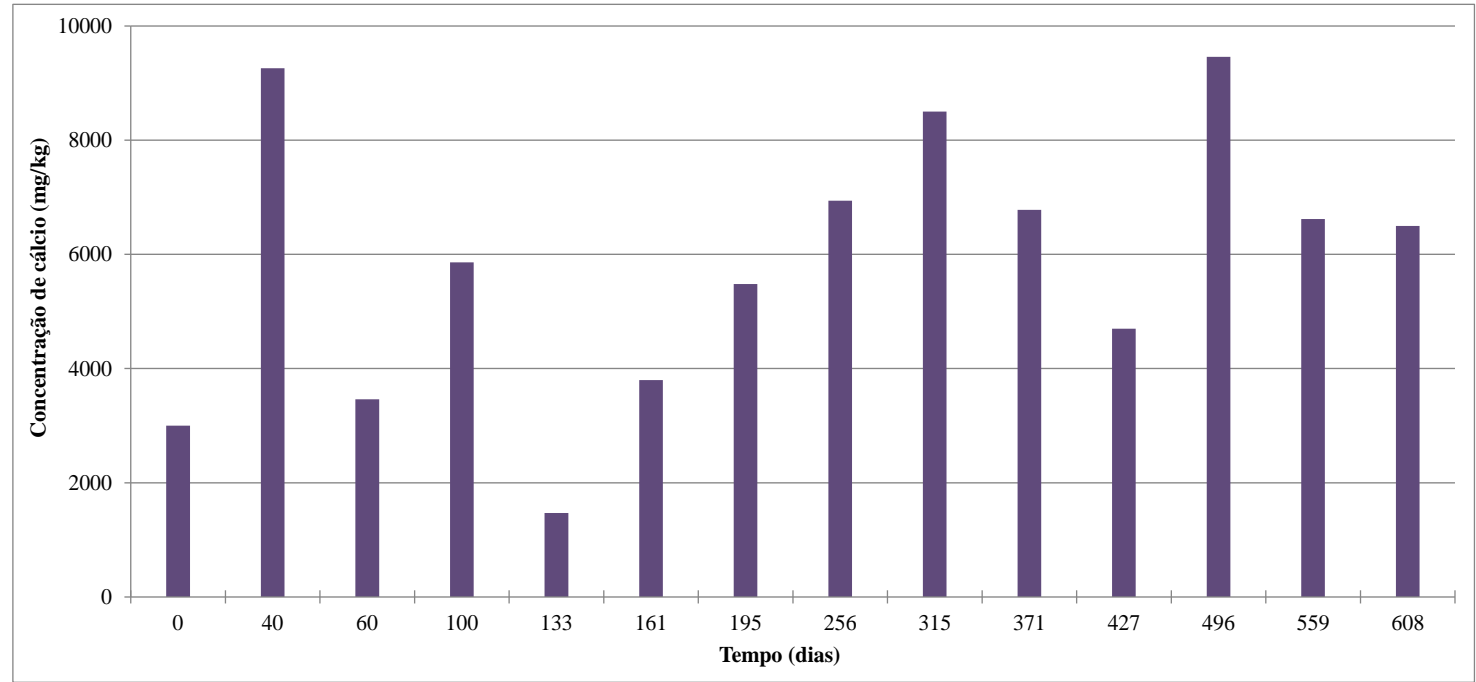

Figura 2 - Concentração de cálcio nos resíduos sólidos urbanos do lisímetro ao longo do tempo. 
Através da Figura 2 percebe-se que a concentração de cálcio variou bastante ao longo do tempo, o que pode ser justificado pela elevada heterogeneidade dos resíduos sólidos urbanos. A concentração de cálcio máxima detectada foi de $9.460,00 \mathrm{mg} / \mathrm{kg}$ em 496 dias de monitoramento.

A concentração de cálcio em todo o monitoramento apresentou valores elevados se comparados com os outros componentes estudados, o que está associado à elevada concentração desse componente em materiais utilizados na construção do lisímetro como a areia e o cimento. Apesar de o cálcio ser um metal alcalino terroso, uma análise das suas concentrações é interessante no ponto de vista de avaliar a fitotoxicidade dos resíduos através da influência da concentração desse elemento na Germinação Relativa das Sementes (GRS) e no Crescimento Relativo das Raízes (CRR), como no estudo realizado por Silva (2012).

\section{CONCLUSÕES}

No início do monitoramento foram detectadas elevadas concentrações de alumínio $(30,40 \mathrm{mg} / \mathrm{kg})$, de manganês $(30,00 \mathrm{mg} / \mathrm{kg})$ e de ferro $(93,80 \mathrm{mg} / \mathrm{kg})$, as quais tendem a diminuir ao longo do tempo, exceto para o caso do ferro que variou durante todo o estudo.

Além disso, os resíduos sólidos urbanos da cidade de Campina Grande-PB foram classificados em "Classe I - Perigosos" por apresentar ao menos um metal com concentração acima do estabelecido pelas normas.

\section{REFERÊNCIAS BIBLIOGRÁFICAS}

ABNT (Associação Brasileira de Normas Técnicas), 2004. Resíduos Sólidos: Classificação. NBR 10.004, 2004.

ABNT (Associação Brasileira de Normas Técnicas), 2004b. Resíduos Sólidos procedimento para obtenção de extrato lixiviado de resíduos sólidos. NBR 10.005: Rio de Janeiro, 2004b. 16p.

ABNT (Associação Brasileira de Normas Técnicas), 2004b. Resíduos Sólidos procedimento para obtenção de extrato solubilizado de resíduos sólidos.NBR 10.006:Rio de Janeiro, 2004b. 7p.

BRITO, A. L. F. Protocolo de avaliação de materiais resultantes da estabilização por solidificação de resíduos. Universidade Federal de Santa Catarina - UFSC, 2007, 179p. Florianópolis, SC. Tese de Doutorado.

CETESB. Companhia de Tecnologia de Saneamento Ambiental. Guia de coleta e conservação de amostras de água. São Paulo, 1986.

CHRISTENSEN, T. H.; KJELDSEN, P.Basic biochemical processes in landfills. In: Christesensen, T. H.; Cossu, R. and Stegmann, R. (Ed), Sanitary landfilling: processes, technology and environmental impact. Academic Press Ltd., Toronto. 1989.

EHRIG, H. J. Leachate quality in: Sanitary landfilling process, techonology and environmntal impact. In: Stegmann R. \&Heyer, K. U. Leachate management: leachate 
generation, collection, treatment and costs. Disponível em: <http://www.ifas_hamburg.de/pdf/leachate.pdf>. 1989.

FERREIRA, M. A. da S. Aplicação de modelos de avaliação qualitativa e quantitativa dos percolados gerados em um aterro sanitário. Dissertação de Mestrado. COPPE/UFRJ. 2006.

GARCEZ, L. R. Estudo dos componentes tóxicos em um biorreator de resíduos sólidos urbanos da Cidade de Campina Grande - PB .Universidade Federal de Campina Grande Campina Grande, 2009.

LEITE, H. E. A. S. Estudo do comportamento de aterros de RSU em um biorreator em escala experimental na cidade de Campina Grande-PB. 220p. Dissertação (Mestrado em Engenharia Civil e Ambiental), Centro de Tecnologia e Recursos Naturais. Universidade Federal de Campina Grande, Campina Grande, 2008.

MELO, M.C. Uma análise de recalques associada abiodegradação no aterro de Resíduos Sólidos da Muribeca. Dissertação de Mestrado, UFPE, 2003.

MESQUITA FILHO, M. V.; SOUZA, A. F. Resposta do tomateiro à aplicação da calagem e da adubação fosfatada. In: Congresso Brasileiro de Olericultura, 26., Salvador, 1986. Resumos; Hortic. Bras, 4:61-66, 1986.

MONTEIRO, V. E. D. Análises Físicas, Químicas e Biológicas no Estudo do Comportamento de Aterro da Muribeca. Tese de doutorado. UFPE. 2003.

MONTEIRO, V. E. D. M; MELO, M. C.; ALCÂNTARA, P. B.; ARÁUJO, J. M.; ALVES, I. R. F. S.; JUCÁ, J. F. T. Estudo do comportamento de rsu em uma célula experimental e suas correlações com aspectos microbiológicos, físicos e químicos. Artigo técnico. Engenharia Sanitária e Ambiental. Vol.11 no3. Rio de Janeiro July/Sept. 2006.

MUlholland, K. L.; DYER, J. A. Pollution prevention: methodology, technologies and practices.New York: American InstituteofChemicalEngineers, 1999.

KRAEMER, M. E. P. A questão ambiental e os resíduos industriais. XXV ENEGEP, Porto Alegre-RS, Brasil, 2005.

PINTO, C. A.; DWECK, J.; SANSALONE, J.J.; CARTLEDGE, F. K.; TITTLEBAUM, M. E.; BÜCHLER, P.M. A study of the early stages of solidification/stabilization of storm water runoff solid residuals in cement using non-conventional DTA.Journal of Thermal Analysis and Calorimetry, v. 80, n. 3, p. 715-720, jun. 2005.

SILVA, A. S. Avaliação da toxicidade dos resíduos sólidos urbanos da cidade de Campina Grande-PB. Dissertação de Mestrado. UFCG. 2012. 